\title{
MODELING PATH EFFECTS IN THREE-DIMENSIONAL BASIN STRUCTURES
}

\author{
By Robert W. Graves* and Robert W. Clayton
}

\begin{abstract}
Path effects for seismic wave propagation within three-dimensional (3-D) basin structures are analyzed using a reciprocal source experiment. In this experiment, a numerical simulation is performed in which a point source is excited at a given location and then the wave field is propagated and recorded throughout a 3-D grid of points. Using the principle of reciprocity, source and receiver locations are reversed. This allows the modeling of path effects into a particular observation site for all possible source locations using only one simulation. The numerical technique is based on the use of paraxial extrapolators and currently tracks only acoustic waves. However, the method is capable of handling arbitrary media variations; thus, effects due to focusing, diffraction, and the generation of multiple reflections and refractions are modeled quite well.

The application of this technique to model path effects for local earthquakes recorded at stations in the Los Angeles area of southern California indicates the strong influence of the 3-D crustal basins of this region on the propagation of seismic energy. The modeling results show that the Los Angeles, San Fernando, and San Gabriel basins create strong patterns of focusing and defocusing for paths into these stations from various source locations. These simulations correlate well with earthquake data recorded at both stations. By comparing these calculations with earthquake data, we can begin to evaluate the importance of these basin effects on observed patterns of strong ground motions.
\end{abstract}

\section{INTRODUCTION}

The physical processes associated with the occurrence of strong motions may be grouped into three basic categories: (1) source effects, (2) site effects, and (3) path effects. The first two account for phenomena that occur locally at the source or the observation site, while the third is related to the wave propagation between these two regions. A substantial amount of work has been done describing the details of the seismic source (e.g., Aki and Richards, 1980, Chapter 3; Heaton, 1982; Wald et al., 1991) and on characterizing the site response due to local geologic conditions in a particular area (e.g., Duke et al., 1971; Kagami et al., 1986; Seale and Archuleta, 1989). In general, it is more difficult to obtain a detailed description of the path effects, especially in regions containing strongly heterogeneous media where phenomena such as multi-pathing or focusing and defocusing of energy become significant. In addition, since every possible source location has a large number of potential observation sites, each with its own unique set of wave propagation paths, this type of analysis can be quite complex. As a result, the path effects are usually combined with the source and site effects to obtain empirical attenuation relationships that are appropriate for a given generalized region (Campbell, 1981; Joyner and Boore, 1981; Hadley et al., 1982; Abrahamson and Litehiser, 1989). 91101.

* Present address: Woodward-Clyde Consultants, 566 El Dorado Street, Pasadena, California 
Recently, several studies have been conducted that address, in detail, the effects of seismic wave propagation through two-dimensional (2-D) heterogeneous media and the impact this has on the observed patterns of strong ground motions. These include analyses of the 1971 San Fernando, California, earthquake (Drake and Mal, 1972; Liu and Heaton, 1984; Vidale and Helmberger, 1988) and the 1985 Michoacán earthquake (Flores et al., 1987; Bard et al., 1988; Sanchez-Sesma et al., 1988; Campillo et al., 1989). These studies found that structural variations along the propagation path can have a profound effect on the amplitude and duration of the recorded seismic signal.

Extending these types of analyses to three-dimensional (3-D) media, Ihnen and Hadley (1986) employed an approximate 3-D ray tracing approach to study the 1965 Seattle, Washington, earthquake. They predicted that ground motions are significantly affected by subsurface structure and soil properties. In particular, they found that the focusing of rays due to subsurface basin structures can lead to a large amplification in ground motion response. More recently, using a fully elastic finite-difference formulation, Frankel et al. (1990) have performed some preliminary analyses of the 3-D path effects for the 1989 Loma Prieta earthquake.

In order to address the complexities of 3-D media for these types of studies, we utilize the one-way paraxial technique described in Graves and Clayton (1990). This approach is different from others presented in the literature in that it provides a full waveform calculation for realistic 3-D structures over a range of frequencies that is of interest to both engineers and seismologists. The technique is limited by the paraxial approximation and the restriction to acoustic media; however, since the method is capable of handling arbitrary media variations, effects due to focusing and defocusing, diffraction, and the generation of multiple reflections and refractions are modeled quite well.

With this technique, path effects of seismic energy propagating into a particular observation site are modeled using a reciprocal source experiment. In this experiment, a point source is excited at the observation site and then the wave field is propagated and recorded throughout a 3-D grid of points. The principle of reciprocity is then used to reverse source and receiver locations. This allows us to model the response at a given site for all possible source locations within a given 3 -D volume using only one simulation.

The method is illustrated with an analysis of the 3-D propagation effects of the greater Los Angeles basin region. In our analysis, data recorded at two stations in this region (PAS and USC) are compared with the results of reciprocal source simulations performed for these two sites. Comparing the data and synthetics in a relative sense for the two sites is useful because many of the complexities regarding the source are removed from the problem. In doing this, differences in the observed signals at the two sites will result primarily from differences in the propagation paths from the source to each of the recording sites. This allows us to verify complexities introduced by the 3-D structure of this region.

\section{Structural Model for the Greater Los Angeles Region}

Our primary goal in the present study is to investigate the effect that the large sediment-filled basins of the greater Los Angeles region have on seismic energy that is propagated through these structures. In order to simplify the numerical parametrization of these structures within the model, we have used 
a simple mathematical description that attempts to mimic the main geomorphic features of the basins. Based on surface geology and available data on depth to basement rock, the regional model was divided into four enclosed basins. Each basin is represented in the model using an ellipsoid. The parameters describing the ellipsoid that best conforms to the known geologic structure of each basin are given in Table 1 . The surface expression of these basins is compared with a geologic map showing surface exposures of Quaternary alluvium in Figure 1. The smooth form of the ellipsoids does not match the details of the actual geology; however, the gross nature of the basins is represented fairly well. Below the surface, the detailed structure of the basins is less well constrained, but the general form of the basins is ellipsoidal in shape (Yerkes et al., 1965; Davis et al., 1989). Since we are mostly concerned with determining the large scale influence of these basins on longer-period seismic wave propagation, the omission of the small scale variation's in structure is an adequate approximation.

The model is completed by specifying one-dimensional (1-D) velocity and density profiles appropriate for the material within each of the basins, as well as specifying a 1-D background medium used to represent the host material around and beneath the basins. The profiles were obtained from sources in the literature and are listed in Table 2. Each profile was chosen to be representative of the average vertical structure within the province. For the background medium, we used the average southern California model given by Hadley and Kanamori (1977), modified to include a thin, low-velocity, near-surface layer to represent the uppermost crust.

\section{Paraxial Modeling Technique}

Ideally, to properly simulate the effects of 3-D structure for comparison with observed patterns of strong ground motions, one would like to model the full elastic wave field. Complete solutions to these types of problems can be formulated using a conventional finite-difference approach (e.g., Kelly et al., 1976; Frankel et al., 1990); however, this is generally not practical due to the large amount of computer memory required by these techniques. Employing the paraxial formulation alleviates the problems associated with limited computer

TABLE 1

Geometry Parameters for Model Basins

\begin{tabular}{|c|c|c|c|c|c|}
\hline Basin Name & Basin Center Location & Rotation Angle & $\begin{array}{c}\text { Major Axis } \\
(\mathrm{km})\end{array}$ & $\begin{array}{c}\text { Minor Axis } \\
(\mathrm{km})\end{array}$ & $\begin{array}{c}\text { Depth } \\
\text { (km) }\end{array}$ \\
\hline Los Angeles & $\begin{array}{l}33.86^{\circ} \mathrm{N} \\
118.12^{\circ} \mathrm{W}\end{array}$ & $56^{\circ}$ & 38.5 & 17.0 & 9 \\
\hline San Bernardino & $\begin{array}{l}34.05^{\circ} \mathrm{N} \\
117.5^{\circ} \mathrm{W}\end{array}$ & $-70^{\circ}$ & 24.0 & 14.2 & 1.5 \\
\hline San Fernando & $\begin{array}{l}34.22^{\circ} \mathrm{N} \\
118.45^{\circ} \mathrm{W}\end{array}$ & $77^{\circ}$ & 14.2 & 7.0 & 4.5 \\
\hline San Gabriel & $\begin{array}{l}34.1^{\circ} \mathrm{N} \\
118.02^{\circ} \mathrm{W}\end{array}$ & $72^{\circ}$ & 13.4 & 7.5 & 3.5 \\
\hline
\end{tabular}

The values for basin center location, rotation angle, major axis, and minor axis were measured from the Geologic Map of California (Jennings et al., 1977). The rotation angle is defined to be the angle between the major axis of the basin and north (counter-clockwise positive). Depths for the Los Angeles, San Gabriel, and San Fernando basins taken from Davis et al. (1989); depth of the San Bernardino basin obtained from Yerkes et $a l$. (1965) and Hadley and Combs (1974). 


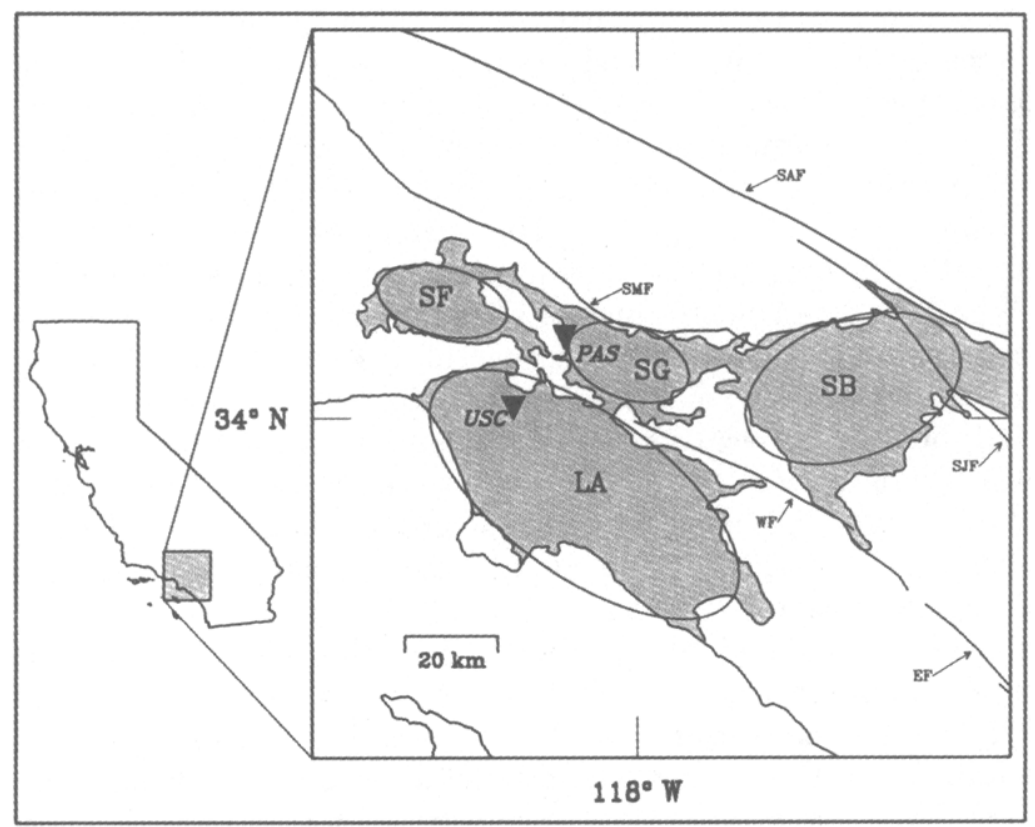

FIG. 1. Map view of the southern California region showing the location of the basins used in the modeling exercise. The shaded area represents surface exposures of Quaternary alluvium (reproduced from Jennings et al., 1977) that are used to define the outlines of the basins. Ellipsoidal basins used in the model are indicated by the oval outlines that delineate the surface expressions of these structures. For reference, these basins are: LA, Los Angeles; SB, San Bernardino; SF, San Fernando; and SG, San Gabriel. Also shown on the map are the major faults of the region: EF, Elsinore Fault; SAF, San Andreas Fault; SJF, San Jacinto Fault; SMF, Sierra Madre Fault; and WF, Whittier Fault, as well as the location of the recording stations PAS and USC (solid triangles).

memory. Unfortunately, the full elastic paraxial system is very complicated and, at the present time, only solutions for simple 2-D models can be calculated with this approach (Graves, 1990). For this reason, we choose to employ the 3-D acoustic paraxial formulation described by Graves and Clayton (1990).

Using an acoustic approach to model what is unquestionably a fully elastic problem may seem like a gross oversimplification. However, this type of approach has been successfully applied in other areas, for example in the analysis of seismic reflection data. Certainly, the technique is not able to model all of the elastic propagation effects (e.g., P-S coupling) or incorporate earthquake source mechanisms and radiation patterns. Nevertheless, the acoustic formulation is useful in modeling focusing and diffraction effects as the wave field is propagated through heterogeneous media. Thus we expect that structures that produce a particular effect in an acoustic simulation (e.g., a crustal wave guide that concentrates and amplifies seismic energy) would also produce similar effects in an elastic simulation.

In order to test the hypothesis, we compare results obtained from an acoustic calculation with those obtained from an elastic calculation for a simulation of the 1971 San Fernando earthquake. Vidale and Helmberger (1988) used a 2-D elastic finite-difference technique to model a profile of three-component strongmotion recordings from this event. Their study found that lateral variations in structure along the profile produced strong effects on the observed seismic signals. These effects include variations in amplitude due to focusing and 
TABLE 2

Velocity and Density Profiles for Southern California Model

\begin{tabular}{|c|c|c|c|c|}
\hline Province & $\begin{array}{l}P \text {-Wave Velocity } \\
(\mathrm{km} / \mathrm{sec})\end{array}$ & $\begin{array}{c}\text { Density } \\
\left(\mathrm{gm} / \mathrm{cm}^{2}\right)\end{array}$ & $\begin{array}{l}\text { Depth to Top } \\
\text { of Layer }(\mathrm{km})\end{array}$ & Reference \\
\hline \multirow[t]{6}{*}{ Los Angeles basin } & 2.1 & 1.8 & 0.0 & \multirow[t]{6}{*}{ Duke et al. (1971) } \\
\hline & 2.4 & 1.9 & 0.75 & \\
\hline & 3.1 & 2.1 & 1.75 & \\
\hline & 3.5 & 2.2 & 3.0 & \\
\hline & 4.3 & 2.3 & 5.0 & \\
\hline & 5.5 & 2.5 & 9.0 & \\
\hline \multirow[t]{2}{*}{ San Bernardino basin } & 2.1 & 1.8 & 0.0 & \multirow[t]{2}{*}{ Hadley and Combs (1974) } \\
\hline & 2.9 & 2.0 & 0.5 & \\
\hline \multirow[t]{5}{*}{ San Fernando basin } & 2.1 & 1.8 & 0.0 & \multirow[t]{5}{*}{ Duke et al. (1971) } \\
\hline & 2.4 & 1.9 & 0.5 & \\
\hline & 3.0 & 2.1 & 1.2 & \\
\hline & 3.5 & 2.2 & 2.5 & \\
\hline & 5.5 & 2.5 & 4.2 & \\
\hline \multirow[t]{4}{*}{ San Gabriel basin } & 2.1 & 1.8 & 0.0 & \multirow{4}{*}{$\begin{array}{l}\text { Inferred from structure } \\
\text { of San Fernando basin }\end{array}$} \\
\hline & 2.4 & 1.9 & 0.5 & \\
\hline & 3.0 & 2.1 & 1.2 & \\
\hline & 3.5 & 2.2 & 2.5 & \\
\hline \multirow[t]{5}{*}{ Background media } & 3.6 & 2.2 & 0.0 & \multirow[t]{5}{*}{ Hadley and Kanamori (1977) } \\
\hline & 5.5 & 2.5 & 2.0 & \\
\hline & 6.3 & 2.7 & 4.0 & \\
\hline & 6.7 & 2.9 & 16.0 & \\
\hline & 7.8 & 2.9 & 32.0 & \\
\hline
\end{tabular}

defocusing of seismic energy and generation of surface waves within the sedimentary basins. Our hypothesis predicts that we would be able to model these same effects using an acoustic formulation of this problem.

The model used in the acoustic simulation is taken from the regional southern California model discussed in the previous section. This model represents a 3-D block of crust extending to a depth of $25 \mathrm{~km}$ and encompassing the entire San Fernando basin, as well as portions of the Los Angeles and San Gabriel basins (Fig. 2). The section labeled $A A^{\prime}$ in this figure roughly corresponds to the location of the profile that was modeled by Vidale and Helmberger (1988). For an acoustic calculation, an isotropic point source was set at a depth of 10 $\mathrm{km}$. This source is driven with a two-sided Gaussian time function having a half-width parameter of $0.6 \mathrm{sec}$. The energy in this source is concentrated in the period range from 1 to $10 \mathrm{sec}$. Ensuring that the entire frequency bandwidth is modeled accurately requires a grid spacing of $0.125 \mathrm{~km}$ in the extrapolation direction and $0.25 \mathrm{~km}$ in the other two dimensions. This results in a model space containing $1.2 \times 10^{7}$ grid points.

Figure 3 plots the envelope of the recorded pressure field as a function of time for a dense line of receivers located just below the surface along the profile $A A^{\prime}$. It is evident that the structural variations in the model produce significant effects in the recorded pressure field. The relatively low-velocity material in the Los Angeles and San Fernando basins tends to trap and channel seismic energy, thus amplifying the strength of the signals observed in these areas as opposed 


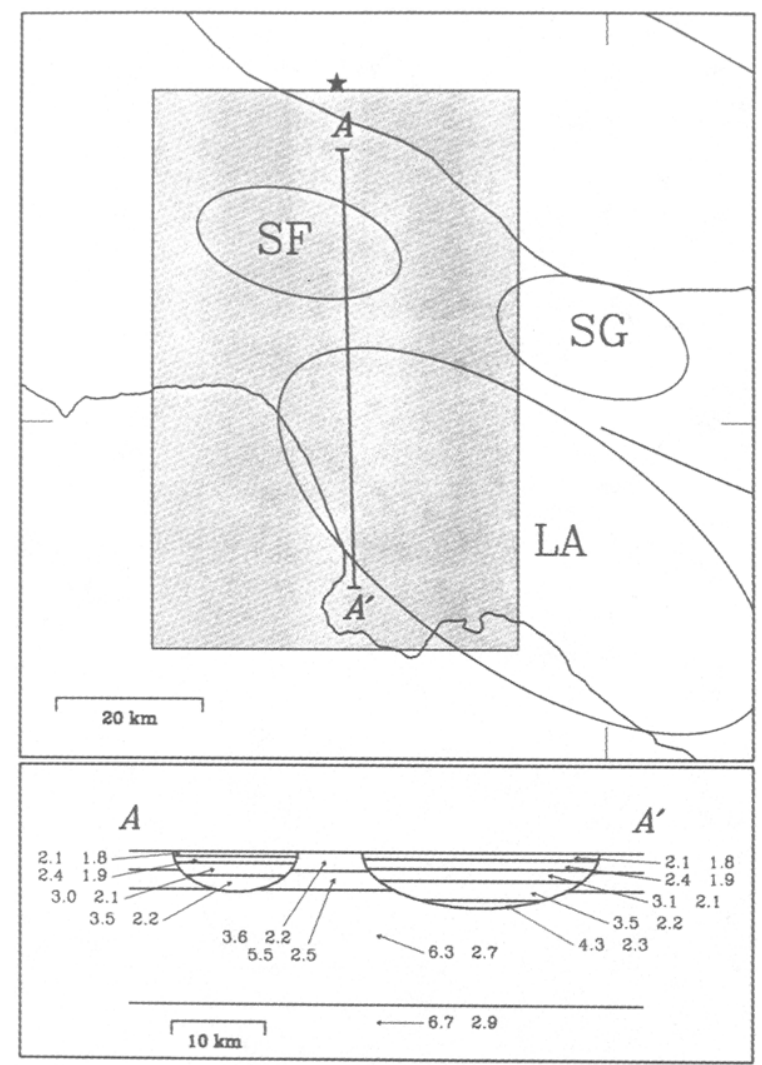

FIg. 2. The top panel shows a map view of the surface expression of the 3-D model (shaded region) used for the acoustic simulation of the San Fernando earthquake. Epicenter is indicated by the star. Basins and faults are the same as shown in Figure 1. The bottom panel displays a vertical cross section of this model taken along the profile $A A^{\prime}$. Paired numbers are $P$-wave velocity $(\mathrm{km} / \mathrm{sec})$ and density $\left(\mathrm{g} / \mathrm{cm}^{3}\right)$ for each of the layers in the model. The bowl-shaped features in this section are the San Fernando (left) and Los Angeles (right) basins. Structurally, these basins are separated by the east-west-trending Santa Monica mountains.

to those signals observed along the ridge of the Santa Monica mountains. In addition, the layered structure within the basins creates a series of multiply refracted and reflected arrivals (surface waves) that propagate across the section with a slow apparent velocity. These surface waves are created at the near source edges of both basins, although some of the surface wave energy originating in the San Fernando basin tunnels through the Santa Monica mountains into the Los Angeles basin.

The results from the elastic simulation are presented in Figure 4, which is a reproduction of Figure 14 from Vidale and Helmberger (1988). The figure plots the envelope of the transverse $(\mathrm{SH})$ component of velocity as calculated with a 2-D elastic finite-difference scheme for a structural model similar to the one shown in Figure 2. We show only the $S H$ component for ease of comparison, although the elastic simulation produces similar effects in the radial and vertical components of velocity (Vidale and Helmberger, 1988). Comparing the $\mathrm{SH}$ results with those from the acoustic calculation shown in Figure 3, we see many striking similarities, e.g., the amplification of energy within the basins and the generation of surface waves. In addition, the elastic calculation pro- 


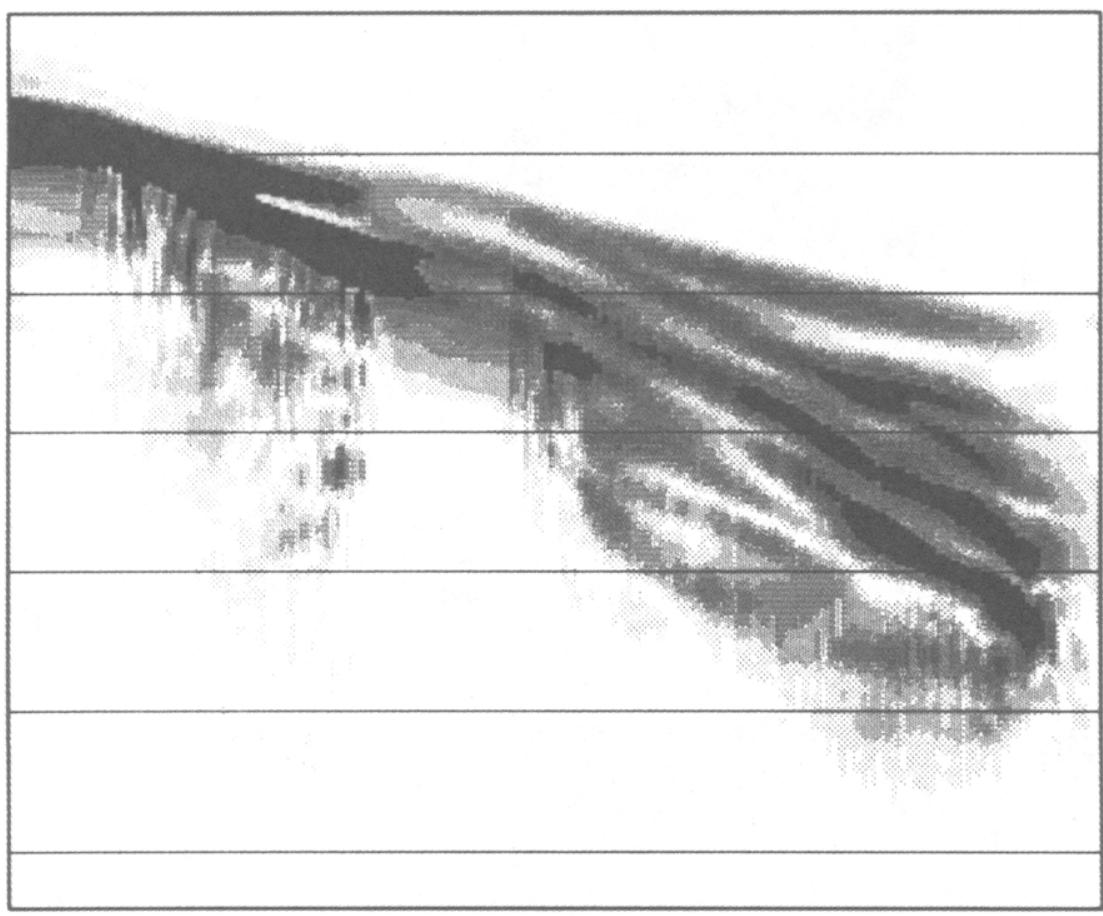

6

12

$10 \mathrm{~km}$

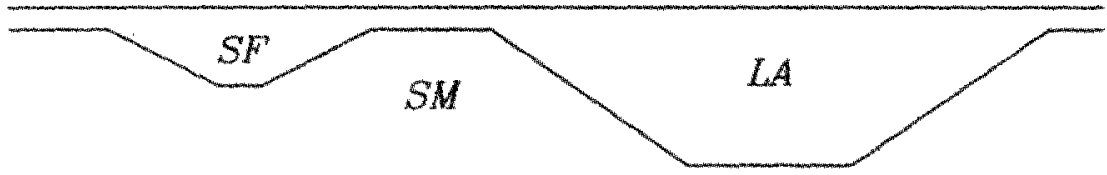

FIG. 3. A record section of the envelope of the observed pressure field along the profile $A A^{\prime}$ shown in Figure 2, as calculated in the acoustic simulation. The intensity of the image is scaled to correspond with the amplitude of the seismic energy that is recorded at a particular time. Thus, the dark portions of the image indicate the highest amplitude arrivals, while the lighter areas indicate arrivals of lesser amplitude. Below the section, the major geologic structures along this profile are indicated. Here LA denotes the Los Angeles basin, SF the San Fernando basin, and SM the Santa Monica mountains.

duces very little backscattered (back toward the source) energy from the edges of the basins. The energy would appear as set of arrivals with a reversed slope to the direct arrivals in Figure 4 . Thus, a single forward pass with the paraxial technique suffices to model most of the energy in the basin's.

In some sense, the similarities in these results are not unexpected, due to the closeness of form between the 2-D $S H$-wave equation and the acoustic-wave equation. In fact, the acoustic results could be made to mimic the $S H$ results more closely by simply changing the time scale in Figure 3 to match that used in Figure 4 . This would be similar to replacing the $P$-wave velocities in the acoustic model with the appropriate $S$-wave velocities and performing the calculation again. Unfortunately, since the $S$ waves do not decouple into $S V$ and $S H$ in the full 3-D problem, there is no 3-D scalar analog of the 2-D $S H$-wave equation. Thus, this type of system would not accurately represent the scattering effects of shear waves within heterogeneous 3-D media. 


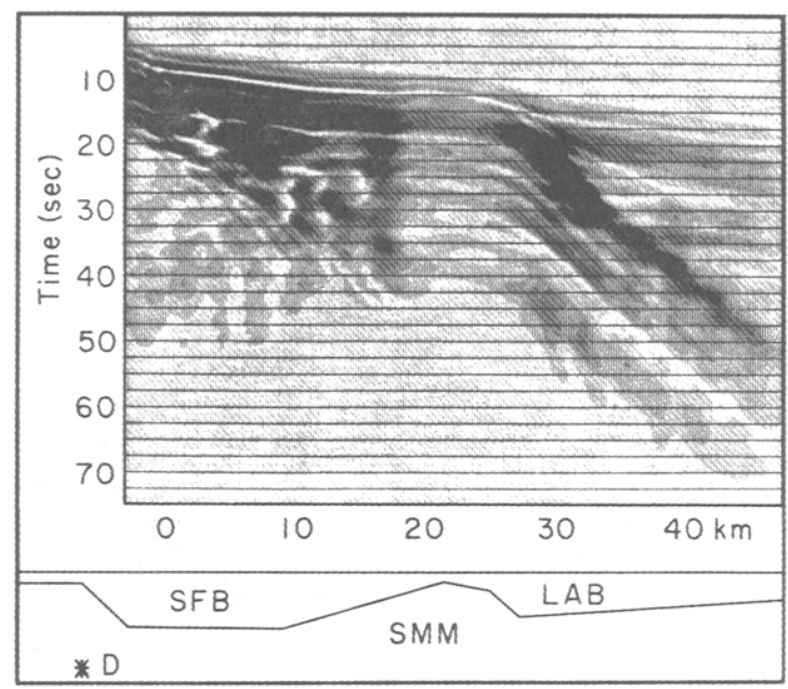

FIG. 4. A record section of the envelope of the transverse component of velocity along a profile similar to $A A^{\prime}$, taken from Vidale and Helmberger (1988). The scaling of this image is similar to that of Figure 3 . The major geologic structures along this profile are again sketched below the section, where LAB denotes the Los Angeles basin, SFB the San Fernando basin, and SMM the Santa Monica mountains. The source location used in the simulation is indicated by the asterisk.

Our opinion is that, given the limitations of current computational hardware, the acoustic paraxial system is the most appropriate formulation to use at the present time because: (1) it is based on fundamental physical principles from which straightforward mathematical derivations can be performed and (2) it provides us with the capability to fully model wave propagation effects within 3-D structures over a realistic range of frequencies.

Although the results of the 2-D and 3-D simulations discussed above are similar, quantifying the effects of $3-\mathrm{D}$ structure on seismic wave propagation requires the modeling of the phenomena in their full $3-\mathrm{D}$ context. This point is illustrated in Figure 5, which plots the peak pressure amplitude recorded on a plane located just below the surface in the acoustic simulation of the San Fernando earthquake. It is clear that the variation of peak amplitudes across the model is quite dramatic. While some of these effects could have been predicted from 2-D simulations, other effects are truly 3-D in nature, e.g., the east-west variation of peak amplitude values across the San Fernando and Los Angeles basins (amplitudes in the northwest portion of the Los Angeles basin are a factor of 3 greater than those recorded in the northeast portion of the basin, at similar source-receiver distances). Effects such as these cannot be predicted from 2-D models.

\section{RECIPROCAL SOURCE EXPERIMENT}

\section{Forward Modeling}

The reciprocal source experiment consists of two numerical simulations; one for the station PAS and one for the station USC (located in Fig. 1). In each simulation, we excite a point source at the given station location and then observe the wave field throughout a 3-D grid of points as it propagates away from the site. Using the principle of reciprocity (Claerbout, 1985, Section 9.4), the wave field observed at a particular grid point in each simulation is the same 


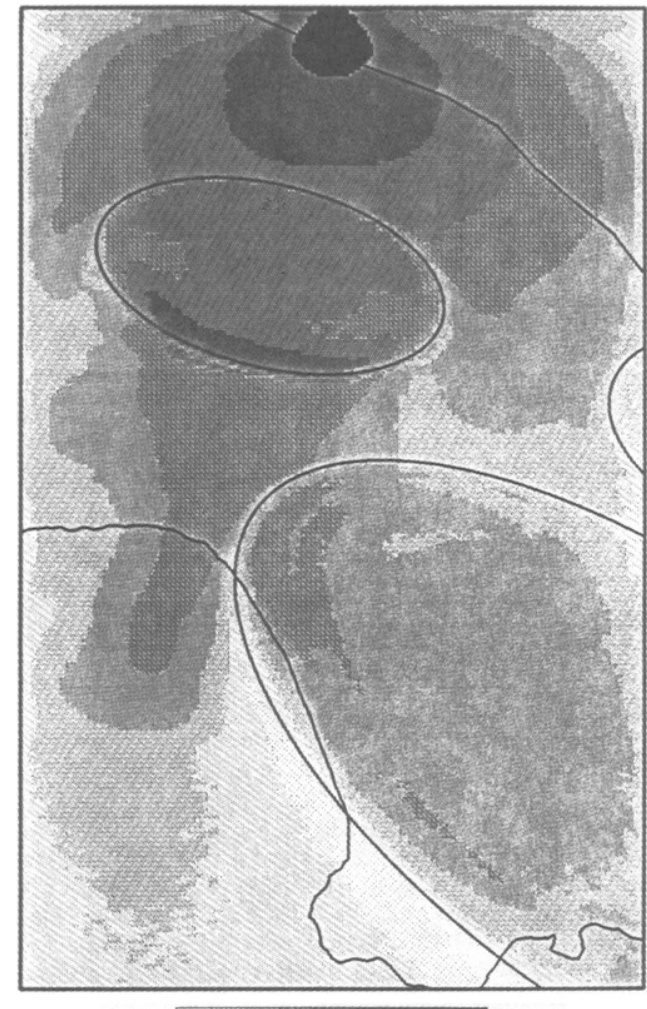

$0 . 1 2 \longdiv { \square } 2 . 2 6$

FIG. 5. Plot of peak pressure amplitude recorded along a plane located just below the surface in the 3-D acoustic simulation of the San Fernando earthquake. The region shown corresponds to the shaded area in the top panel of Figure 2, with the basin outlines, coastline, and faults indicated by the solid lines. A logarithmic $\left(\log _{10}\right)$ scaling has been applied to the absolute peak amplitude values. Note the strong influence of the basin structures on the observed pattern of peak amplitude attenuation. The anisotropic nature of the source (i.e., weak radiation to the east and west) results from the paraxial approximation used in the calculation. This effect is only significant for energy leaving the source at high propagation angles and has little affect on the region of interest.

as would be observed at the station if the source had been located at that grid point. Since we are using isotropic point sources and modeling a scalar wave field, the relative orientation or radiation pattern of the receivers and sources is not an issue. By comparing the results obtained from the two simulations, we can quantify the relative path effects into these two sites for any given source location.

Each model used in the simulations represents a 25 -km-deep block of crust covering an area of 120 by $120 \mathrm{~km}$. The surface expression of these models is shown in Figure 6. Note that the region of overlap between the two models encompasses a large portion of southern California. All grid points lying within this region of overlap represent potential source locations that can be compared at both stations.

For each simulation, the source is located just below the surface, centered at the corresponding station location shown in Figure 6. In using the one-way paraxial technique for the simulations, we must take care to ensure that the region of interest lies within the $60^{\circ}$ angular accuracy limitations of this method. For example, if we were to extrapolate vertically downward from the 


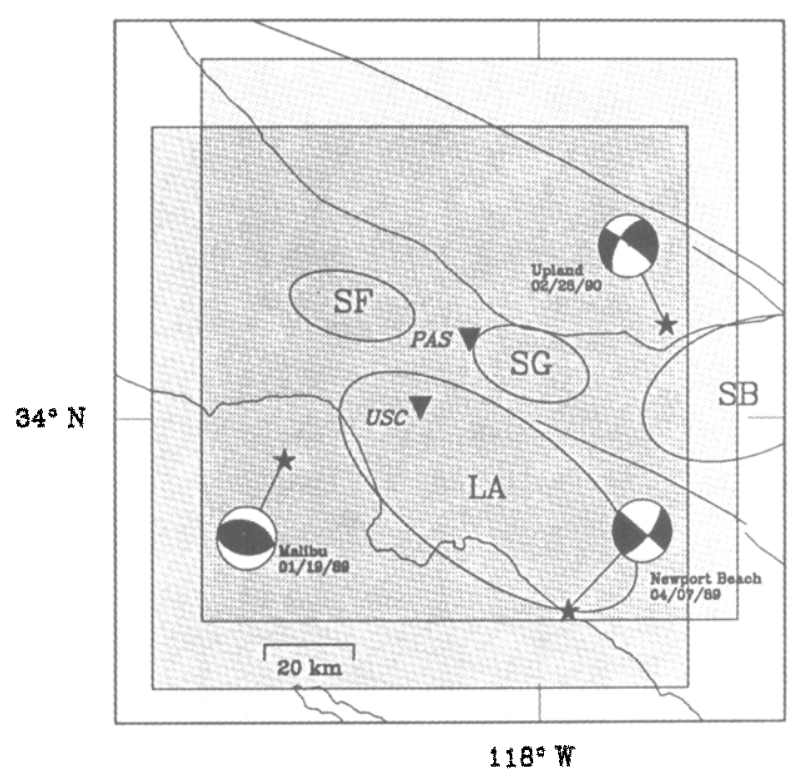

FIG. 6. Map view showing surface expression of 3-D models used for the reciprocal source experiment. The model for station PAS is denoted by the region of light shading and the model for station USC by the region of medium shading. Each station site is located in the center of its respective model and corresponds to the location of the numerical source used in the simulations. The area of heavier shading represents the region of overlap between the two models. Also shown are the locations and focal mechanisms of the three events (location is denoted by a star) used for the data analysis. Basins and faults are the same as shown in Figure 1.

source point, propagation paths to grid points at or near the surface would be at about $90^{\circ}$ with respect to the extrapolation direction and thus would not be modeled very accurately. Setting the extrapolation direction in the horizontal plane alleviates this problem yet we are now faced with a lateral variation in accuracy. This problem can be avoided by dividing the model into four submodels, performing simulations for each of these submodels and then recombining the results from these submodels in such a way as to minimize the region for which the solution has limited accuracy. This procedure is illustrated schematically in Figure 7.

There is still a limited region of poor accuracy that occupies a narrow cone extending vertically downward from the source. This region could be modeled with the addition of a fifth submodel, but this is not done since the region represents only a small subset of the entire volume that is being investigated. Also, modeling the multiple reverberations among the predominantly horizontal layers of the model would require multiple passes of the paraxial extrapolators.

The source-time function used in the simulations is a two-sided Gaussian function with a half-width of $0.6 \mathrm{sec}$. The bandwidth of this source lies in the period range from 1 to $10 \mathrm{sec}$. Grid spacing in each of the submodels is $0.125 \mathrm{~km}$ in the extrapolation direction and $0.25 \mathrm{~km}$ in the other two dimensions. Over $9.2 \times 10^{7}$ grid points are needed to obtain the final model for each simulation.

Since the numerical simulations have been computed using an acoustic formulation initiated with an isotropic point source, the resulting wave fields are only affected by the distance of propagation and the structure sampled along the propagation path. The effects of anelastic attenuation (seismic $Q$ ) have 


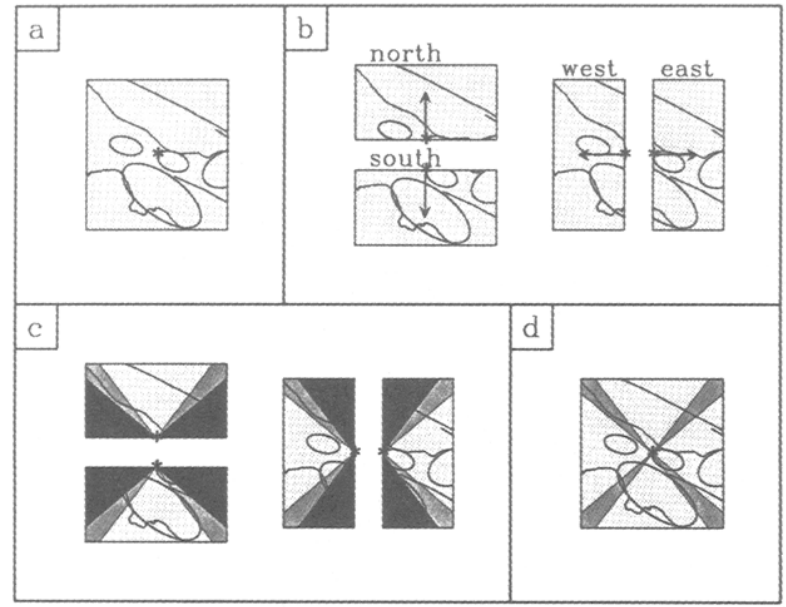

FIG. 7. Schematic representation of model construction. (a) Desired region to be modeled. Source location is denoted by asterisk. (b) Submodels used to perform the actual simulations. The four submodels are chosen to represent the areas north, south, east, and west of the source, respectively. The arrows indicate the extrapolation direction used for each of the submodels. The paraxial solution is accurate for propagation angles out to $60^{\circ}$ with respect to the extrapolation axis. (c) Map view of the weighting function as applied to each of the submodels. Regions of light shading are all pass, regions of medium shading have a linear taper with increasing azimuth, and regions of dark shading are zero. Denoting the azimuthal direction by $\theta(\theta=0$ being the extrapolation axis), the specific form of the weighting function is given by

$$
W(\theta)= \begin{cases}1, & 0^{\circ} \leqq|\theta| \leqq 40^{\circ} ; \\ \left(50^{\circ}-|\theta|\right) / 10^{\circ}, & 40^{\circ} \leqq|\theta| \leqq 50^{\circ} \\ 0, & 50^{\circ} \leqq|\theta| \leqq 90^{\circ}\end{cases}
$$

(d) Final model obtained from the summation of the four submodels. The areas of medium shading indicate regions of overlap between adjacent submodels. The weighting function is designed to sum to a value of unity for all grid points in the final model.

not been included in the modeling process, although this is not a necessary restriction of our numerical method.

Figure 8 shows wave field time slices for the two simulations, PAS and USC, recorded on a plane just below the surface of each model. As the seismic energy propagates through the basin structures, distortions in both the timing and amplitude of the advancing wave field become apparent. Some of the observed effects include: (1) waves traveling within the basins are slowed relative to waves traveling outside of the basins; (2) energy is channeled and focused by the basin structures, thus amplifying the strength of waves observed in these areas; and (3) multiple arrivals and surface waves develop within the basins as the wave field propagates laterally across these structures.

The peak pressure amplitude recorded along four depth planes is plotted in Figure 9 for both simulations. The effects due to the basin structures are most noticeable near the surface and diminish with increasing depth. The peak recorded amplitudes are, in general, higher within the basins than they are in regions outside the basins, although shadow zones (regions of relatively low amplitudes) and bright spots (regions of relatively high amplitudes) are created in areas both inside and outside of the basins, depending on the relative geometry of the basins and the source. Some of these effects can be observed from 2-D models (e.g., Hill et al., 1990); however, the power of the focusing 


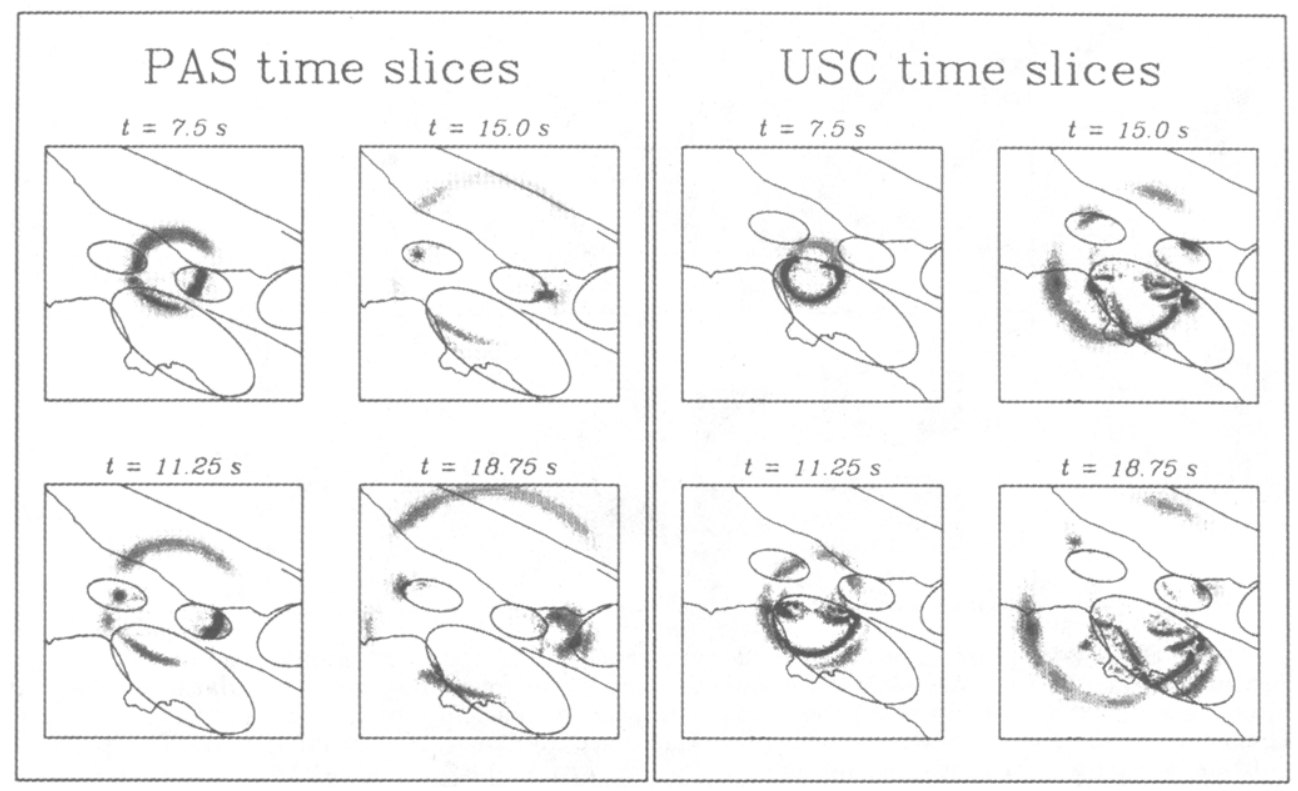

FIG. 8. Snapshots of the envelope of the wave field recorded along a plane just below the surface for the PAS (left panel) and USC (right panel) simulations at four selected time steps. The area shown in these images represents the surface exposure of the two models depicted in Figure 6 . For each image, the intensity of the wave field is scaled to correspond with the amplitude of the seismic energy that is observed at that time. The dark portions of the images indicate the highest amplitude arrivals, while the lighter areas indicate arrivals of lesser amplitude. Note the strong influence of the basins on the observed wave field.

observed in the 3-D simulations cannot be accurately modeled using a 2-D approach (Graves and Clayton, 1990) and effects such as the strong azimuthal variation in amplitude attenuation seen in this figure would be impossible to predict without incorporating 3-D structural variations into the model.

The influence of the basin structures on the observed patterns of amplitude attenuation is illustrated in more detail in Figure 10, which compares amplitude decay curves for two 3-D numerical calculations. The first calculation is for a model in which the media varies only as a function of depth. The vertical structure of this model is the same as the background or host material used for the regional southern California model (Table 2). The second set of curves is taken from the PAS simulation. In order to simplify the comparison, we will examine the results along radial lines extending horizontally outward from the source location at depths of $0,5,10$, and $15 \mathrm{~km}$. Although the results from the host calculation are azimuthally invariant, the results from the PAS calculation are highly dependent on azimuth (see Fig. 9). To obtain a representative slice of the basin structure from the PAS model, the results from this simulation were taken along radial lines heading due east from the source point for each of the four depths. Along this azimuth, the surface line in the PAS model cuts across portions of the San Gabriel and San Bernando basins, while the three depth lines all lie beneath these basin structures.

As might be expected, the results for the host model calculation show a simple monotonic decrease in amplitude with increasing distance for all depth slices. The results for the PAS simulation, on the other hand, show a strong influence due to the 3-D basin structures. Near the source, energy is channeled and focused with the San Gabriel basin. This effect not only amplifies the strength 


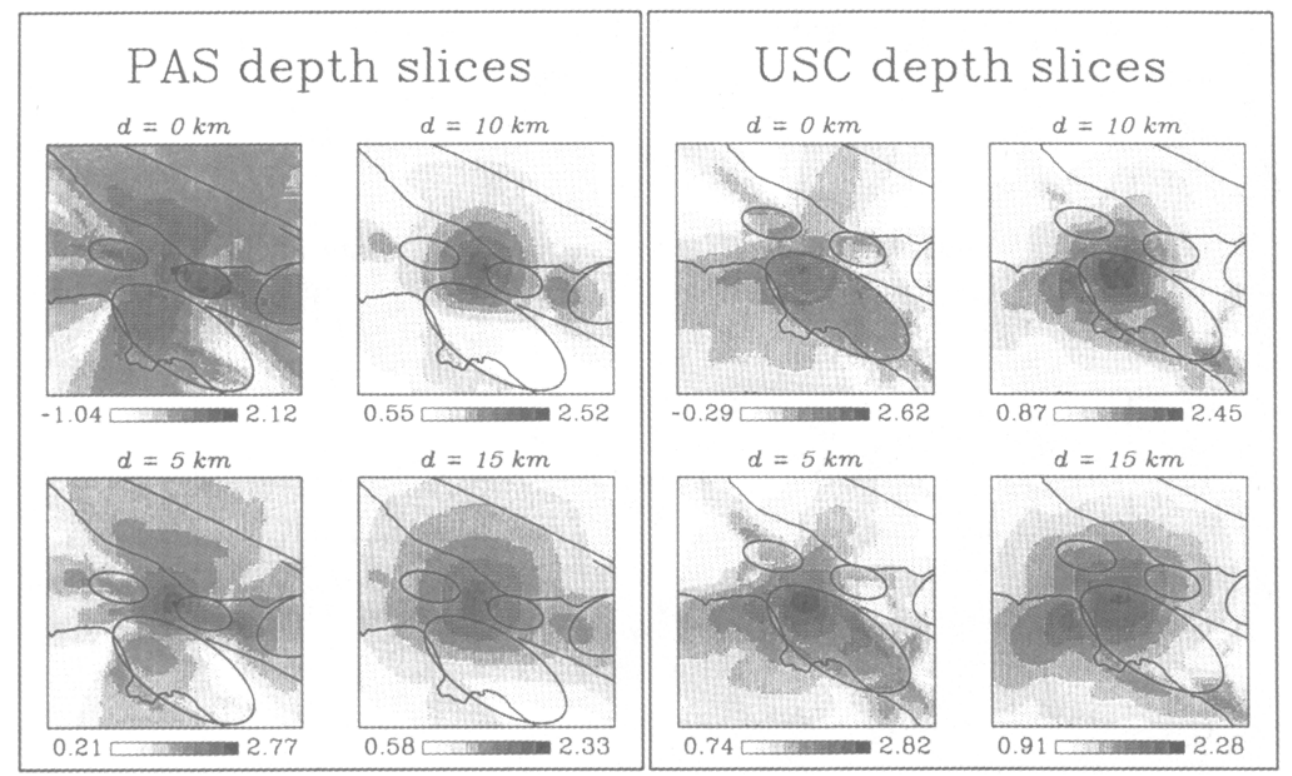

FIG. 9. Peak acoustic amplitude recorded along four depth slices from the PAS (left panel) and USC (right panel) simulations. For orientation purposes, we have superimposed the surface exposures of the basin outlines, faults, and coastline on each set of images. In each image, a logarithmic scaling $\left(\log _{10}\right)$ has been applied to the absolute peak amplitude values. The presence of the basin structures creates a complex pattern of amplitude decay throughout the entire modeled region.

of the signals recorded inside the basin but also creates a shadow zone in the region behind the basin at a distance range of just beyond $20 \mathrm{~km}$ from the source. The shadow zone is very strong near the surface and extends to below $5 \mathrm{~km}$ in depth. With increasing depth, the two calculations become more similar, although the PAS results still show elevated amplitudes for distances beyond $30 \mathrm{~km}$.

Focusing of energy results from constructive interference, in space and time, of waves that have been refracted or reflected by different structures throughout the modeled region. For areas of strong focusing, the superposition of the waves is very coherent, with the phase of the interfering wavefronts being nearly identical. If these individual wavefronts are shifted in phase by various amounts, then the intensity of focusing will change. Such a phase shift could result from variations in the model structure that would delay or advance waves scattered from different regions. Assuming that a phase shift of a quarter wavelength or greater will begin to alter the observed interference pattern, we can obtain a measure of the length scale of the structural variations required to produce this effect for the period range we have modeled. The numerical simulations are peaked at about 2-sec period, which gives a characteristic wavelength on the order of $10 \mathrm{~km}$. The quarter wavelength criterion suggests that structures with length scales on the order of 2 to $3 \mathrm{~km}$ or greater may begin to affect the intensity of focusing. It is reasonable to expect that the actual basin structures contain variations on this order that are not modeled accurately using the ellipsoidal parametrization (see Fig. 1). Although these variations may affect the intensity of focusing, they should not alter the general pattern of focusing and defocusing observed in the results. 


\section{Peak Amplitude Comparison}
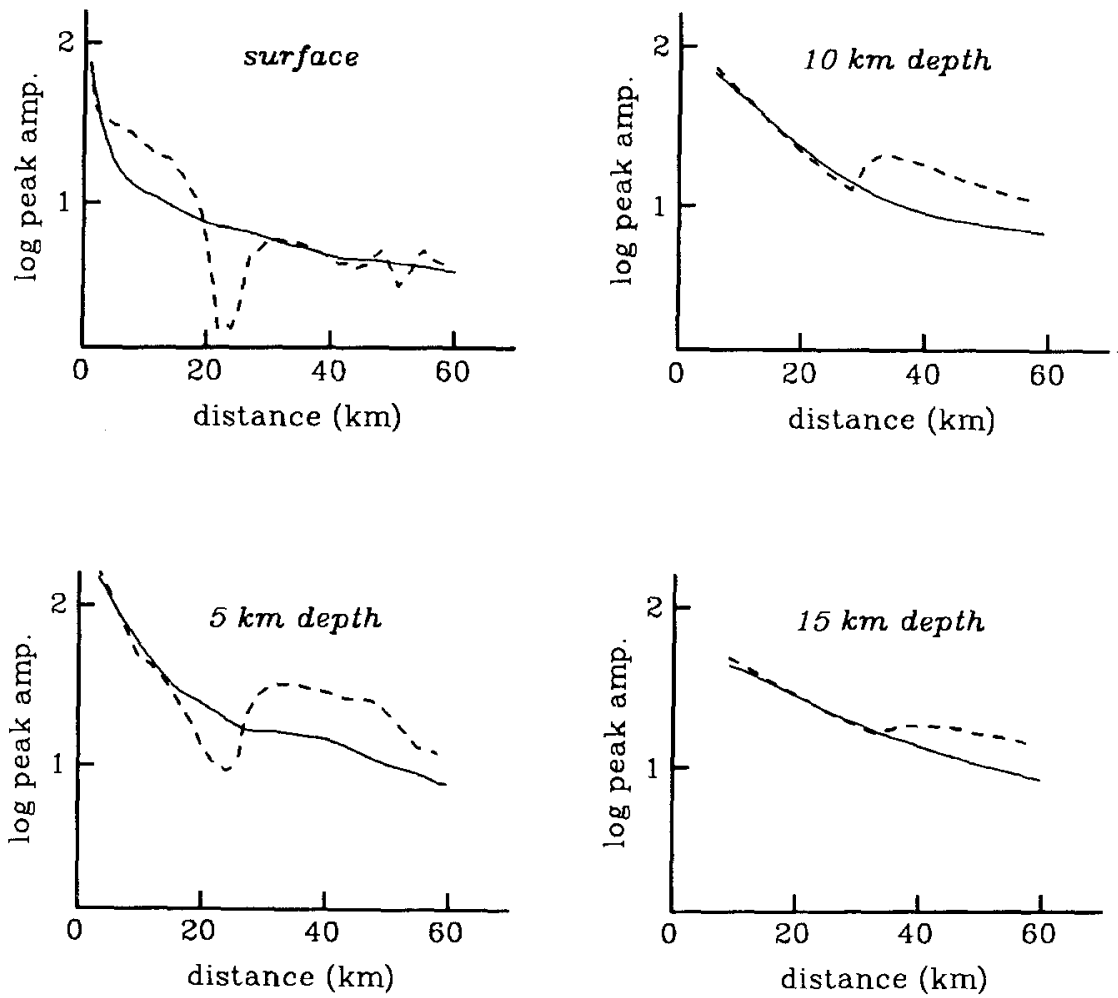

FIG. 10. Comparison of peak amplitude decay as a function of horizontal source/receiver distance at four selected depths for two 3-D numerical calculations. A logarithmic scaling $\left(\log _{10}\right)$ has been applied to the observed peak amplitude values. The first set of results (solid line in each graph) is for a laterally homogeneous model with a vertical structure given by the host material used for the regional southern California model (Table 2). The second set of curves (dashed line in each graph) represents results obtained along radial lines heading due east from the source point in the PAS simulation.

The above simulations can be used as a numerical check to verify that our simulations satisfy the principle of reciprocity. If the simulations were parameterized correctly, then the waveform observed at the USC site for the source located at PAS should be the same as the waveform observed at the PAS site for the source located at USC. A comparison of the two waveforms is shown in Figure 11. The agreement between these results is very good, both in the timing and amplitude of the various phases. From this comparison, we conclude that reciprocity does not exist between the sources and receives in each of the numerical simulations.

Applying the principle of reciprocity to each of the calculations, we can view the simulation results as a set. of seismograms observed at a particular site, PAS or USC, for a variety of source locations. In addition, since all of the sources have the same strength, we are able to easily compare the results of the two calculations. This allows us to investigate the relative nature of the path 


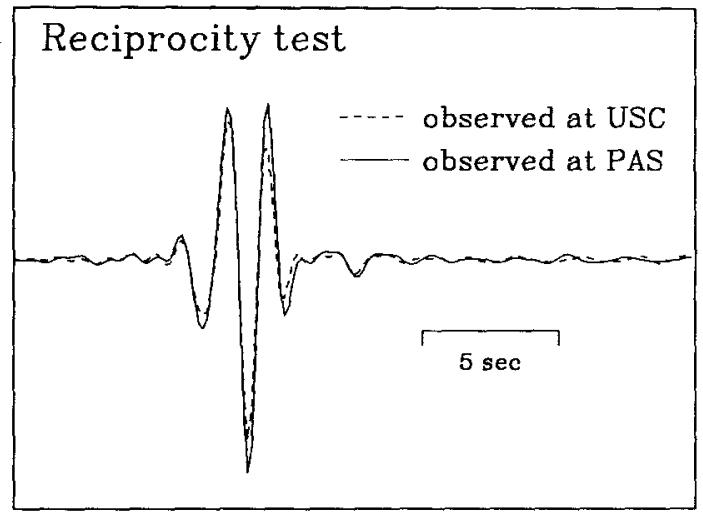

FIG. 11. Numerical test of source/receiver reciprocity. The dashed line is the waveform observed at USC for a source located at PAS and the solid line is for the reciprocal calculation. The traces are plotted relative to the same amplitude scale.

TABLE 3

Locations and Focal Parameters for Studied Events

\begin{tabular}{lccccccc}
\hline Earthquake & \multicolumn{1}{c}{ Date } & \multicolumn{1}{c}{ Location } & $M_{L}$ & $\begin{array}{c}\text { Depth } \\
(\mathrm{km})\end{array}$ & Strike & Dip & Rake \\
\hline Malibu & $19 \mathrm{Jan} 89$ & $33.92^{\circ} \mathrm{N}$ & 5.0 & 13.8 & $-71^{\circ}$ & $45^{\circ}$ & $99^{\circ}$ \\
Newport Beach & $7 \mathrm{Apr} 89$ & $\begin{array}{l}118.62^{\circ} \mathrm{W} \\
33.63^{\circ} \mathrm{N}\end{array}$ & 4.6 & 11.6 & $-50^{\circ}$ & $90^{\circ}$ & $160^{\circ}$ \\
Upland & $28 \mathrm{Feb} 90$ & $\begin{array}{l}117.93^{\circ} \mathrm{W} \\
34.18^{\circ} \mathrm{N}\end{array}$ & 5.5 & 6.0 & $212^{\circ}$ & $60^{\circ}$ & $-6^{\circ}$ \\
& & $117.69^{\circ} \mathrm{W}$ & & & & & \\
\hline
\end{tabular}

The parameters for the Malibu and Newport Beach events were obtained from Hauksson (1990). Parameters for the Upland event are from Dreger and Helmberger (1991).

effects into these two sites for any possible source located within the volumetric region of overlap of the two models (Fig. 6).

\section{Data Analysis}

Three events are compared with the simulations. A map view of epicentral locations for these events is shown in Figure 6. Table 3 lists the locations and focal parameters for each of these events.

Broadband recordings of the vertical component of velocity as observed at the two stations for each event are plotted in Figure 12. Due to the flat spectral response of the broadband instruments used in this study, we can view the data shown in Figure 12 as representing the Green's function response of the Farth (including anelastic attenuation) convolved with the appropriate source time function for each event. For the small events used in this study, the source-time function can be adequately approximated as a delta function, and thus we can regard the data as just the Green's functions for elastic wave propagation through the Earth. The brevity of the source process allows us to examine the path effects for any given frequency range by simply applying a bandpass filter to the data. In order to match the frequency bandwidth of the modeling results, 


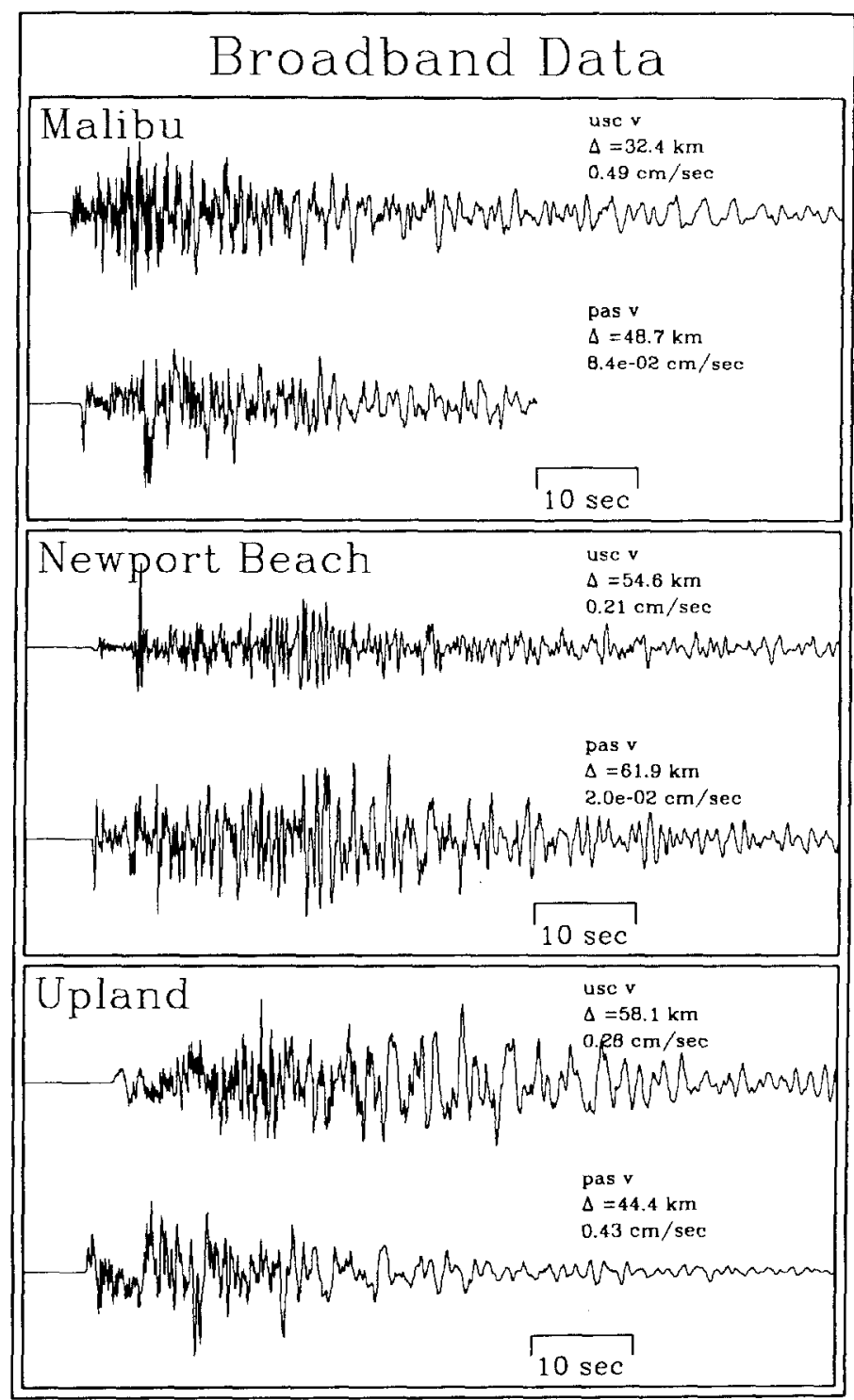

Fig. 12. Broadband recordings of the vertical component of velocity as observed at the stations PAS and USC for the three events listed in Table 3 . Traces are plotted relative to origin time for each event. Peak recorded velocity is listed above each trace.

the data have been filtered with the same Gaussian time functions used to drive the numerical simulations. The filtered data are plotted in Figure 13.

Analyzing these data, some general statements can be made about the characteristics of the observations recorded at each station. First, the coda observed in the USC records is, in general, longer than that seen in the records from PAS. The longer coda at USC develop primarily from the interaction of the propagating wave field with the complicated structure of the Los Angeles basin. In addition, there is a much wider range in the ratio of the peak amplitudes observed at the two stations compared to values predicted using empirically derived amplitude attenuation curves (Joyner and Boore, 1981). This is demon- 


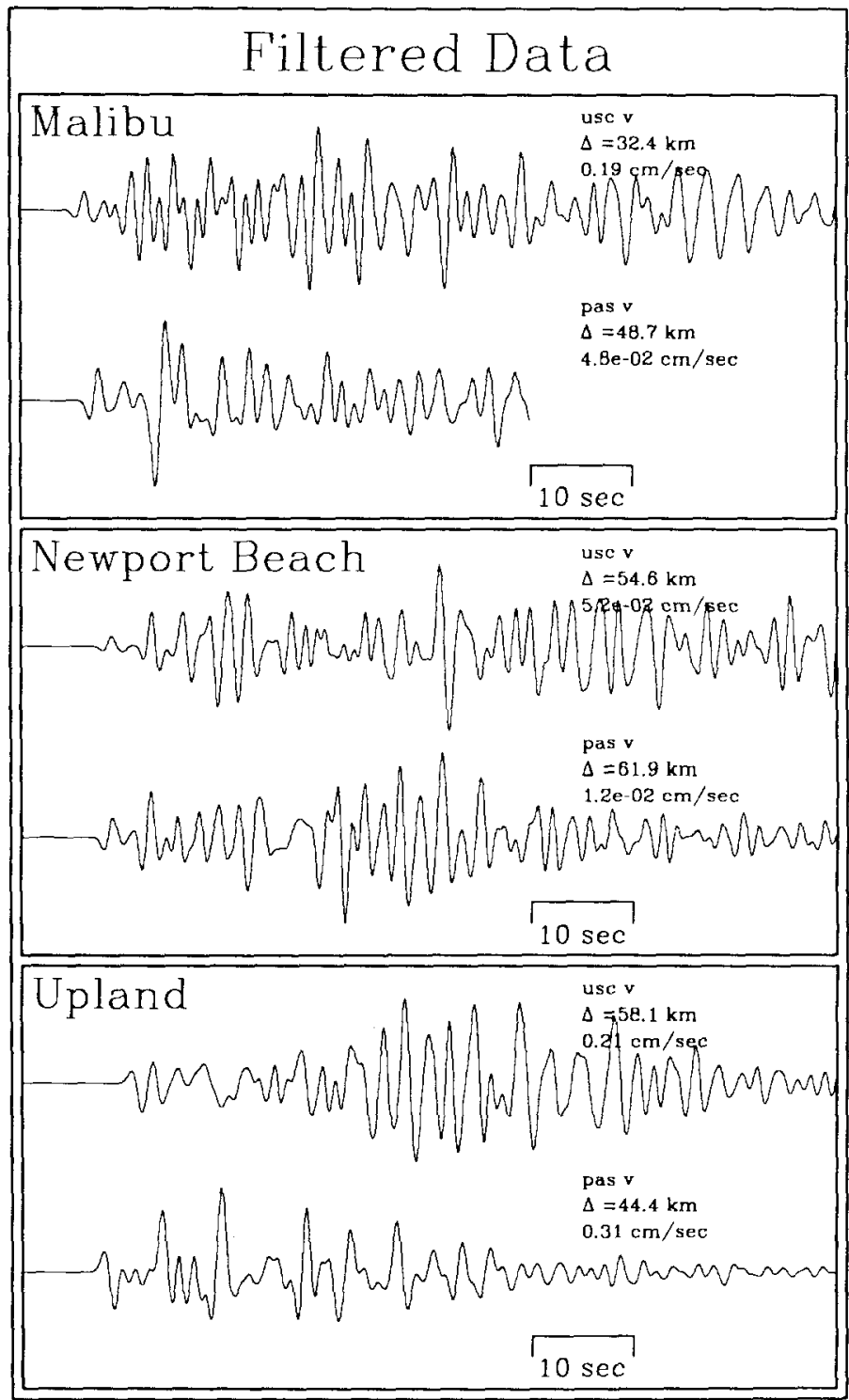

FIG. 13. Filtered velocity records obtained by convolving the broadband records shown in Figure 12 with the Gaussian time function used to drive the source in the numerical simulations. Energy in these traces is concentrated in the period range from 1 to $10 \mathrm{sec}$. The peak recorded velocity of the filtered records is listed above each trace.

strated in Table 4, which compares the measured peak amplitude ratios from the data (USC relative to PAS) to the values obtained from the empirical relationships. The values from the standard curves are corrected for station distance and site response.

To measure the accuracy of the standard curves in predicting the observed amplitude ratios, we introduce the parameter $\delta$ defined by

$$
\delta=\ln (P / D)
$$


TABLE 4

\begin{tabular}{|c|c|c|c|}
\hline \multicolumn{4}{|c|}{$\begin{array}{c}\text { Comparison of Observed and EmpIRICAL } \\
\text { Peak Amplitude Ratios }\end{array}$} \\
\hline Earthquake & $\begin{array}{c}\text { (USC/PAS) } \\
\text { Data }\end{array}$ & $\begin{array}{c}\text { (USC/PAS) } \\
\text { Standard Curve }\end{array}$ & $\delta$ \\
\hline Malibu & 4.0 & 2.5 & -0.47 \\
\hline Newport Beach & 4.3 & 1.7 & -0.93 \\
\hline Upland & 0.68 & 1.0 & 0.39 \\
\hline
\end{tabular}

Standard curve values are from Joyner and Boore (1981). We have used the soft-rock curves for USC and the hard-rock curves for PAS.

where $P$ is the predicted amplitude ratio and $D$ is the observed value. If $\delta=0$, then the predicted value matches the observation; $\delta<0$ indicates an underestimate, and $\delta>0$ indicates an overestimate. From Table 4, it is clear that none of the predicted values does a good job of matching the observations, with the largest discrepancy, $\delta=-0.93$ for the Newport Beach event, corresponding to a difference of greater than a factor of 2.5. It is apparent that the data are showing the effects of some physical process that has not been accounted for properly in the standard scaling relation, namely the effects of focusing and defocusing of energy along the propagation path.

Synthetics seismograms were obtained from the reciprocal source models for locations corresponding as closely as possible to the locations of the three events discussed above. Since the results of the numerical simulations were retained only on $1-\mathrm{km}$ square grids at the depths of $0,5,10$, and $15 \mathrm{~km}$, we are not able to match the exact location for each event. However, the modeled event locations will never be more than $\pm 0.5 \mathrm{~km}$ laterally, or more than $\pm 2.5 \mathrm{~km}$ in depth from the reported location of the actual event. In all cases, this difference is only a small fraction of the total propagation length and thus should not have a great impact on the results. Figure 14 compares the observed and synthetic waveforms for the first arriving energy as recorded at the two stations for each event. For these events, the first arriving energy represents the direct $P$ wave that has been refracted upward from the deeper layers in the crust. In this figure, the data and synthetics are both plotted relative to the origin time of each particular event. The absolute timing of the synthetics has been normalized to best match the timing of the observed record at USC for each event.

For all three events, the relative timing of the observations at the two stations is matched very well by the synthetics. The poorest match is for the Newport Beach event, which shows a misalignment in time of only about 0.25 sec for the observation at PAS.

Also shown in this figure are the observed and predicted amplitude ratios for the first arrivals from each event. Differences in amplitude due to radiation pattern should not be significant, since the two stations are located fairly close to one another with respect to the epicentral distance for each event. In addition, the angle of incidence of the direct $P$ wave will be similar for the two stations. Thus, the ratio of the amplitudes for the vertical component recordings should give an accurate indication of the relative scaling of the direct $P$-wave amplitude between the two stations for each event.

Comparing the observed and predicted values, we see a good match for the Malibu and Newport Beach events, but a rather poor fit for the Upland event. 


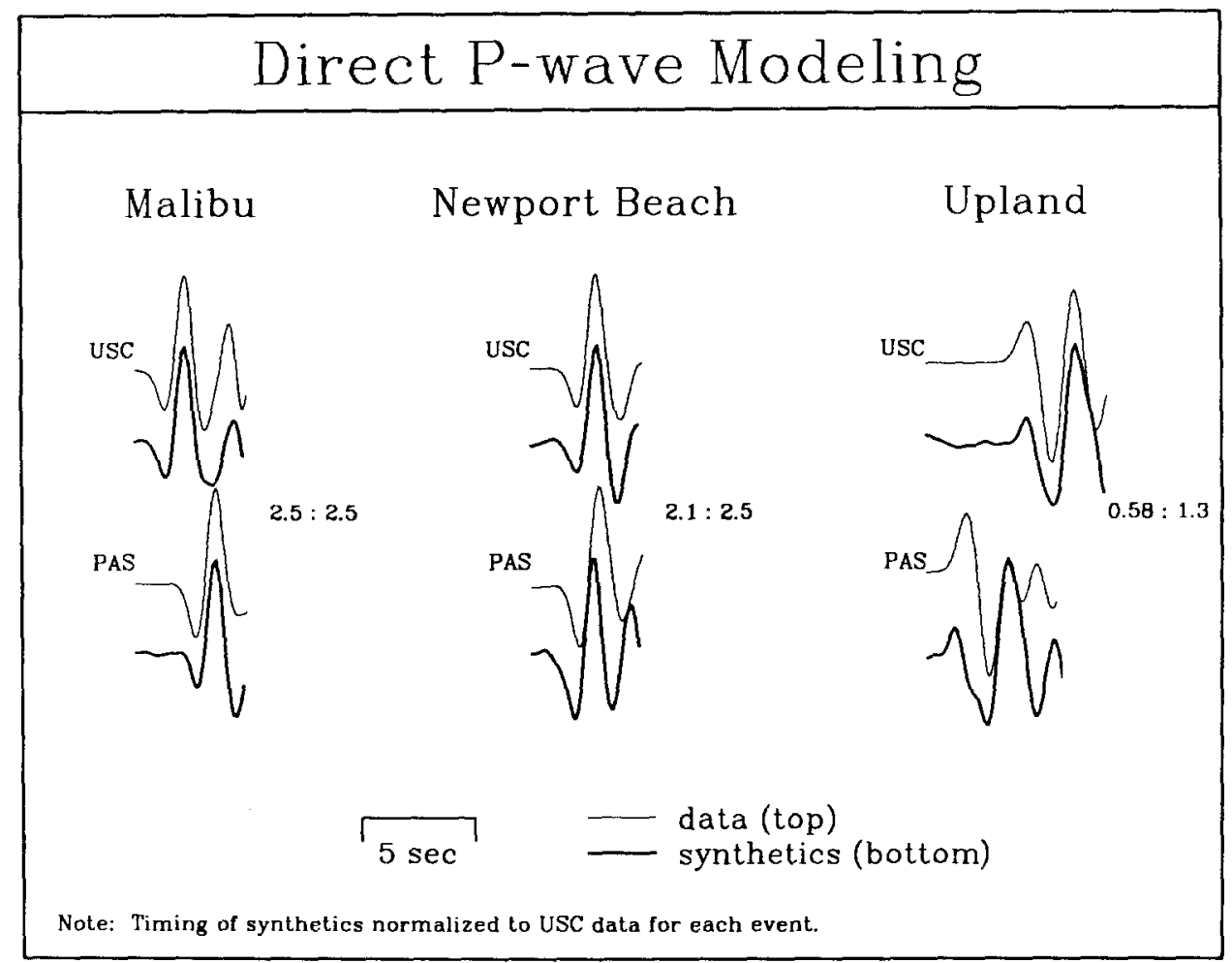

FIG. 14. Direct $P$-wave modeling using results from the reciprocal source calculations. Absolute timing of the synthetics is normalized to align the records observed at USC; thus, a mismatch in timing will show up as a misalignment of the waveforms observed at PAS. Shown to the right of each set of traces is a pair of numbers in the form $R_{d}: R_{s}$. These numbers represent the ratio of the peak recorded amplitudes (USC/PAS) for the data, given by $R_{d}$, compared to the predicted value obtained from the synthetics, given by $R_{s}$. If the two numbers are the same, the predicted amplitude ratio matches the observed value.

The poor match to the Upland data can be explained to a certain extent by the complicated source function of this event. As determined by Dreger and Helmberger (1991), the Upland event is best fit by a double source model with a time lag of 0.75 sec between the two spatially distributed sources. For a complex source such as this, effects such as directivity and pulse interference can have significant influence on the amplitudes of the first arrivals. In order to properly simulate this behavior, the results of the reciprocal source experiment could be used as Green's functions to represent the rupture process of various segments across a finite fault plane. In light of the preliminary nature of the present study, we will defer this type of analysis for future work.

Figure 15 displays the full synthetic waveforms for each of the modeled events. Although, the synthetics cannot match the details of the observed waveforms shown in Figure 13, they do exhibit the same general characteristics that are seen in the data for each event. For example, the simulated records at USC for each event show a generally longer coda as compared to the simulations for PAS. Furthermore, as shown in Table 5, for each event, the ratio of the peak amplitudes predicted by the synthetics provides a much better match to the observations than the values obtained from the standard curves (Table 4). In this case, the poorest fit, $\delta=0.40$ for Newport Beach, corresponds to a difference factor of only 1.5 . 


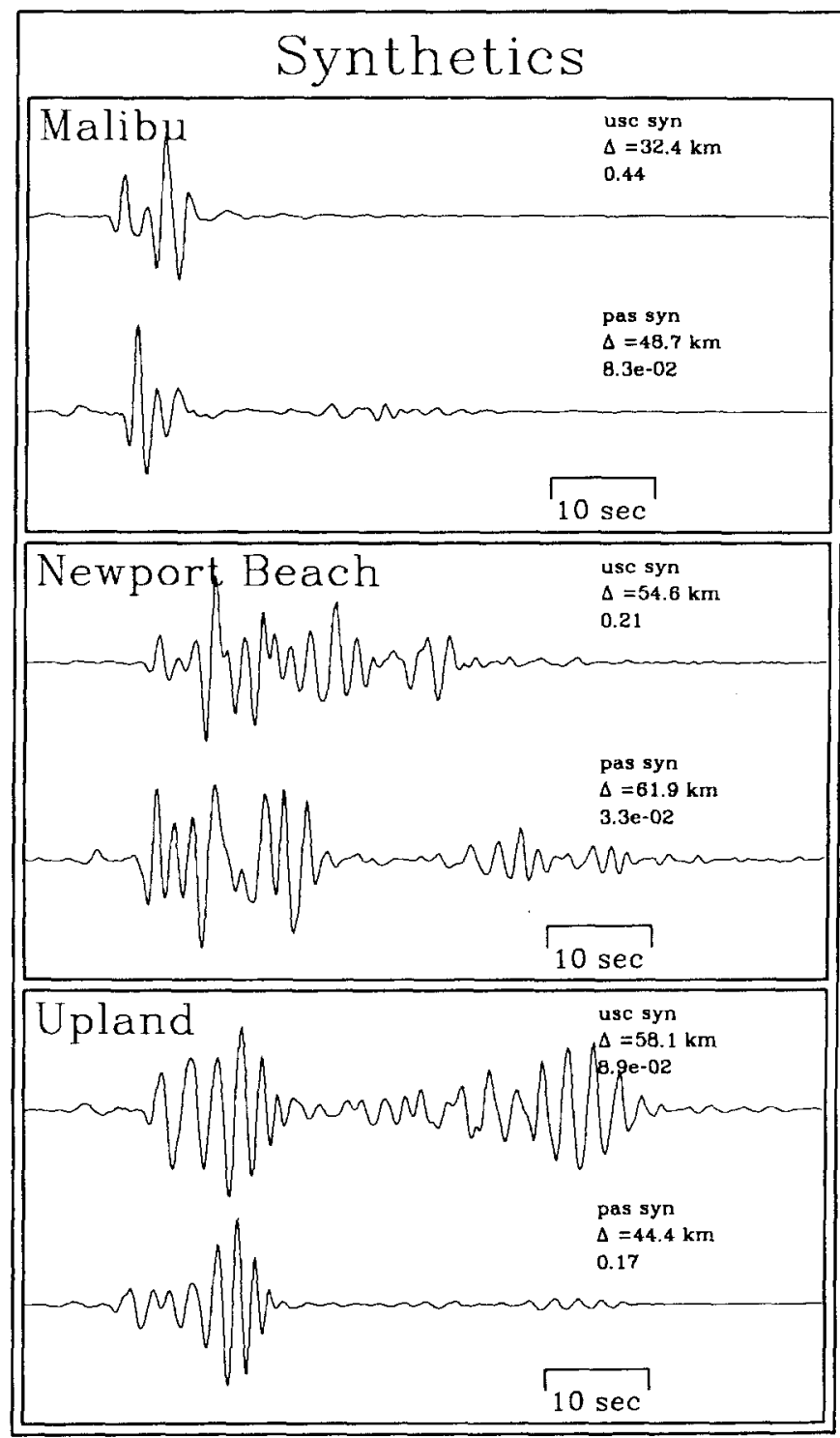

FIG. 15. Complete synthetic waveforms obtained from the reciprocal source calculations for each of the three events. Traces are plotted relative to origin time for each event. Peak acoustic amplitude is listed above each trace.

TABLE 5

COMPaRison OF OBSERVEd AND SYNTHETIC

Peak Amplitude Ratios

\begin{tabular}{lccr}
\hline Earthquake & $\begin{array}{c}\text { (USC/PAS) } \\
\text { Data }\end{array}$ & $\begin{array}{c}\text { (USC/PAS) } \\
\text { Synthetics }\end{array}$ & $\delta$ \\
\hline Malibu & 4.0 & 5.3 & 0.28 \\
Newport Beach & 4.3 & 6.4 & 0.40 \\
Upland & 0.68 & 0.52 & -0.27 \\
\hline
\end{tabular}




\section{Discussion AND CONCLUSIONS}

We have applied our new technique to investigate the path effects for local earthquakes recorded at two southern California stations. Although our approach uses an approximate numerical modeling technique based on an acoustic formulation of the problem, the preliminary results presented here demonstrate the viability of the method to model these effects for realistic earth structures. The modeling results indicate that the presence of the large sediment-filled basins in the Los Angeles region has a great impact on wave fields propagating through these structures. In particular, the low-velocity material within the basins tends to channel and focus seismic energy, thus amplifying the strength of the waves observed in these areas. In addition, depending on the relative geometry of the source with respect to the basins, a complex pattern of shadow zones and bright spots is created in areas both inside and outside of the basins. These effects cannot be modeled with simple site response functions.

One of the difficulties in performing this type of analysis deals with the parametrization of a realistic 3-D model to describe the region of interest. For the present study, we have used a relatively simple model to describe a region that contains some very complicated geologic structures. It would be useful to conduct a sensitivity study to investigate the impact that various changes to the current model would have on the nature of the modeling results. For example, one approach might be to develop a more appropriate model by parameterizing the basin outlines using a detailed contour map of depth to basement rock. Certainly, the ellipsoidal basins used for the present model are too smooth to accurately represent the details of the actual basin structures.

Another area of concern that has not been addressed in detail in the present study is the incorporation of anelastic attenuation within the modeling process. This can be done with a simple model of attenuation (i.e., constant $Q$ ) and applied to the existing results, or it could involve more elaborate schemes that include a spatially variable $Q$ operator into the numerical modeling technique. The effects of attenuation can be quite important, particularly in the low-velocity layers within the basins where $Q$ values can be small (see, for example, Duke et al., 1971). By neglecting these effects, our results may predict amplitudes that are too large for energy that has traveled predominately in the near-surface layers within the basins. This may account for some of the mismatch in the peak amplitude ratios for the data and synthetics shown in Table 5. For example, in the modeling of the Newport Beach event, the record at USC is dominated by surface waves generated within the Los Angeles basin, while at PAS the surface waves are of comparable magnitude to the direct $P$ wave (Fig. 15). Therefore, we speculate that accounting for the effects of attenuation will have a greater impact on the USC results for this event than it will for the PAS results. The net effect would be to reduce the peak amplitude of the USC record by a greater amount than would be observed at PAS. This would bring the predicted peak amplitude ratio into better agreement with the observed value. A similar argument can be applied to the other events as well.

The results of the reciprocal source experiment are very encouraging. Using this technique allows us to model all possible source locations for a given observation site and within a given 3-D volume using only one simulation. This approach offers a powerful tool for use in the investigation of path effects for seismic wave propagation through heterogeneous 3-D structures. Eventually, 
we would like to couple this approach with a more accurate model of seismic wave propagation, such as the full elastic system. In doing this, we can then include effects due to realistic earthquake sources as well as address the problems associated with coupling between $P$ and $S$ energy.

\section{ACKNOWLEDGMENTS}

We would like to thank Amoco Foundation Inc. for the generous fellowship support of R. W. G. during this study. Some of the computations were done on a Convex C1/XP purchased under NSF Grant EAR-8721205. We also thank Donald V. Helmberger and Paul G. Somerville for suggestions to this work. Contribution no. 4988, Division of Geological and Planetary Sciences, California Institute of Technology, Pasadena, California.

\section{REFERENCES}

Abrahamson, N. A. and J. J. Litehiser (1989). Attenuation of vertical peak acceleration, Bull. Seism. Soc. Am. 79, 549-580.

Aki, K. and P. G. Richards (1980). Quantitative Seismology, W. H. Freeman, San Francisco.

Bard, P.-Y., M. Campillo, F. Nicollin, and F. J. Sánchez-Sesma (1988). A theoretical investigation of large and small scale amplification effects in the Mexico City valley, Earthquake Spectra 4, $609-634$.

Campbell, K. W. (1981). Near-source attentuation of peak horizontal acceleration, Bull. Seism. Soc. Am. 71, 2039-2070.

Campillo, M., J. C. Gariel, K. Aki, and F. J. Sánchez-Sesma (1989). Destructive strong ground motion in Mexico City: source, path, and site effects during the great 1985 Michoacán earthquake, Bull. Seism. Soc. Am. 79, 1718-1735.

Claerbout, J. F. (1985). Fundamentals of Geophysical Data Processing, Blackwell, Oxford.

Davis, T. L., J. Namson, and R. F. Yerkes (1989). A cross section of the Los Angeles area: seismically active fold and thrust belt, the 1987 Whittier Narrows earthquake, and earthquake hazard, J. Geophys. Res. 94, 9644-9664.

Drake, L. A. and A. K. Mal (1972). Love and Rayleigh waves in the San Fernando Valley, Bull. Seims. Soc. Am. 62, 1673-1690.

Dreger, D. S. and D. V. Helmberger (1991). Complex faulting deduced from broadband modeling of the 28 February 1990 Upland earthquake $\left(M_{L}=5.2\right)$ Bull. Seism. Soc. Am. 81, 1129-1144.

Duke, C. M., J. A. Johnson, Y. Kharraz, K. W. Campbell, and N. A. Malpiede (1971). Subsurface site conditions and geology in the San Fernando earthquake area, UCLA-ENG-7206, School of Engineering, UCLA, Los Angeles, California.

Flores, J., O. Novaro, and T. H. Seligman (1987). Possible resonance effect in the distribution of earthquake damage in Mexico City, Nature 326, 783-785.

Frankel, A., S. Hough, P. Friberg, and R. Busby (1990). Analysis and modeling of waveforms of Loma Prieta aftershocks recorded on a dense array in Sunnyvale, California, EOS 71, 1456.

Graves, R. W. (1990). Modeling seismic wave propagation using paraxial extrapolators, Ph.D. Thesis, California Institute of Technology, Pasadena, California.

Graves, R. W. and R. W. Clayton (1990). Modeling acoustic waves with paraxial extrapolators, Geophysics 55, 306-319.

Hadley, D. M. and J. Combs (1974). Microearthquake distribution and mechanisms of faulting in the Fontana-San Bernardino area of Southern California, Bull. Seism. Soc. Am. 64, 1477-1499.

Hadley, D. M. and H. Kanamori (1977). Seismic structure of the Transverse Ranges, California, Geol. Soc. Am. Bull. 88, 1469-1478.

Hadley, D. M., D. V. Helmberger, and J. A. Orcutt (1982). Peak acceleration scaling studies, Bull. Seism. Soc. Am. 72, 959-979.

Hauksson, E. (1990). Earthquakes, faulting, and stress in the Los Angeles Basin, J. Geophys. Res. 95, 1.5365-15394.

Heaton, T. H. (1982). The 1971 San Fernando earthquake: a double event?, Bull. Seism. Soc. Am. 72, 2037-2062.

Hill, J., H. Benz, and G. Schuster (1990). Propagation and resonance of $S H$ waves in the Salt Lake Valley, Utah, Bull. Seism. Soc. Am. 80, 23-42

Ihnen, S. M. and D. M. Hadley (1986). Prediction of strong ground motion in the Puget Sound region: the 1965 Seattle earthquake, Bull. Seism. Soc. Am. 76, 905-922. 
Jennings, C. W., R. G. Strang, and R. A. Rogers (1977). Geologic map of California, scale 1:750,000, California Division of Mines and Geology, Sacramento, California.

Joyner, W. B. and D. M. Boore (1981). Peak horizontal acceleration and velocity from strong motion records including records from the 1979 Imperial Valley, California earthquake, Bull. Seism. Soc. Am. 71, 2011-2038.

Kagami, H., S. Okada, K. Shiono, M. Oner, M. Dravinski, and A. K. Mal (1986). Observation of 1 to 5 -second microtremors and their application to earthquake engineering. Part III. A two-dimensional study of the site effects in the San Fernando Valley, Bull. Seism. Soc. Am. 76, 1801-1812.

Kelly, K. R., R. W. Ward, S. Treitel, and R. M. Alford (1976). Synthetic seismograms: a finite-difference approach, Geophysics 41, 2-27.

Liu, H. L. and T. H. Heaton (1984). Array analysis of the ground velocities and accelerations from the 1971 San Fernando, California earthquake, Bull. Seism. Soc. Am. 74, 1951-1968.

Sánchez-Sesma, F. J., S. Chávez-Perez, M. Suárez, M. A. Bravo, and L. E. Pérez-Rocha (1988). On the seismic response of the Valley of Mexico, Earthquake Spectra 4, 569-590.

Seale, S. H. and R. J. Archuleta (1989). Site amplification and attenuation of strong ground motion, Bull. Seism. Soc. Am. 79, 1673-1696.

Vidale, J. E. and D. V. Helmberger (1988). Elastic finite-difference modeling of the 1971 San Fernando, California earthquake, Bull. Seism. Soc. Am. 78, 122-141.

Wald, D. J., D. V. Helmberger, and T. H. Heaton, (1991). Rupture model of the 1989 Loma Prieta earthquake from the inversion of strong motion and broadband teleseismic data. Bull. Seism. Soc. Am. 81, 1540-1572.

Yerkes, R. F., T. H. McCulloh, J. E. Schoellhamer, and J. G. Vedder (1965). Geology of the Los Angeles basin, California: an introduction, U.S. Geol. Surv. Profess. Pap. 420-A, 1-57.

Woodward-Clyde Consultants

566 El Dorado Street

Pasadena, California 91101

(R.W.G.)
SEISMOLOGICAL Laboratory

California Institute of Technology

Pasadena, California 91125

(R.W.C.)

Manuscript received 19 February 1991 